\title{
Is Evolution a Chance Process?
}

\section{DENIS R. ALEXANDER}

The Faraday Institute for Science and Religion, University of Cambridge, United Kingdom dra24@hermes.cam.ac.uk ORCID: 0000-0002-2498-5428

\begin{abstract}
It is commonly thought that evolution is a chance process, an idea found in popular writings on evolution, but also in academic writing in a broad range of scientific disciplines: scientific, philosophical and theological. One problem is that words such as 'chance' and 'random' are used with a range of different meanings according to context, and in evolutionary biology the word 'chance' is sometimes used in a way that is different from its use in mathematics and philosophy. The present article aims to clarify the range of meanings and to argue the case that the evolutionary process is far from being a 'theory of chance' from biological, mathematical, or indeed philosophical and theological perspectives.
\end{abstract}

Keywords: Random; mutation; natural selection; convergence; providence.

\section{Introduction}

When Charles Darwin published The Origin of Species in 1859 it was widely presented as a theory that depended on 'chance', thereby leading to some natural anxieties about the theory's implications. The reader's concerns were not mollified by the observation that in the $6^{\text {th }}$ edition published in 1872 the idea of 'chance' still seemed to play a central role, Darwin writing that: 
As many more individuals of each species are born than can possibly survive; and as, consequently, there is a frequently recurrent struggle for existence, it follows that any being, if it vary however slightly in any manner profitable to itself, under the complex and sometimes varying conditions of life, will have a better chance of surviving, and thus be naturally selected (Darwin 1888).

The variation upon which natural selection operates in the 'struggle for life' is also a matter of chance, but then Darwin corrects himself by writing that:

I HAVE hitherto sometimes spoken as if the variations-so common and multiform with organic beings under domestication, and in a lesser degree with those under nature-were due to chance. This, of course, is a wholly incorrect expression, but it serves to acknowledge plainly our ignorance of the cause of each particular variation (Darwin 1888).

So the word 'chance' can be used in Darwin's writings simply to express our ignorance concerning the actual mechanisms involved. Darwin was also insistent that the composition of living things in a certain habitat defined by its history and by its environment was very far from being due to 'chance': When we look at the plants and bushes clothing an entangled bank, we are tempted to attribute their proportional numbers and kinds to what we call chance. But how false a view is this! (Darwin 1888). The reason why it was false, Darwin explains, is because of natural selection:

But if variations useful to any organic being ever do occur, assuredly individuals thus characterised will have the best chance of being preserved in the struggle for life; and from the strong principle of inheritance, these will tend to produce offspring similarly characterised. This principle of preservation, or the survival of the fittest, I have called Natural Selection (Darwin 1888).

Darwin was naturally upset when his readers did not understand his use of the word 'chance' in The Origin of Species. For example, John Herschel (1792-1871), mathematician, astronomer, and polymath, was one of the most famous natural philosophers (scientists) of his era and referred to by Darwin himself in the Origin as "one of our greatest philosophers", someone 
for whom Darwin had huge respect. This helps explain why Darwin was so upset when, having read the Origin, Herschel referred to his new theory as the "law of higgledy-piggledy" (Carey 2004). Darwin was deeply disappointed by this comment, writing to his friend the geologist Charles Lyell: "What exactly this means I do not know, but evidently it is very contemptuous. If true this is a great blow and discouragement.” To be fair on Herschel, as a brilliant mathematician, the (to him) messy biological theory simply did not have the mathematical elegance that he expected to see in a physical law. In any case, he had written years earlier to Charles Lyell (in 1836) to say that God does not act by a "miraculous process", but by a "natural" series of "intermediate causes". It was not the natural processes that Herschel was worried about, more that the theory just looked so inelegant.

Much water has flowed under the bridge since Darwin first penned his theory, and it is a distinctly different theory today than it was in 1859 . Ironically, given Herschel's mathematically based misgivings, after natural selection as a mechanism for evolution had gone into decline following Darwin's death in 1882, it was mathematicians who came to the rescue, baptizing natural selection into population genetics in a fusion that we now call the "neo-Darwinian synthesis". Three famous figures were associated with this shift in thinking: the British Marxist J.B.S. Haldane, the Anglican British eugenicist R.A. Fisher, and the American Sewall Wright who was a professor at the University of Chicago - an eclectic group indeed. Biologists at that time were so unused to mathematical treatments of their subject that Fisher's first paper submitted to the journal of the London Royal Society was turned down because no one could understand it! However, once explained, it was clear that this new approach was very useful, and it has been so ever since.

Today a modern view of the role of 'chance' in evolution is well expressed by a popular writer on evolutionary biology, Richard Dawkins, who puts the point firmly:

Take, for instance, the issue of "chance", often dramatized as blind chance. The great majority of people that attack Darwinism leap with almost unseemly 
eagerness to the mistaken idea that there is nothing other than random chance in it. Since living complexity embodies the very antithesis of chance, if you think that Darwinism is tantamount to chance you'll obviously find it easy to refute Darwinism! One of my tasks will be to destroy this eagerly believed myth that Darwinism is a theory of "chance". (Dawkins 1986, p. xi)

But here Dawkins is using the word 'chance' with a particular meaning in mind, so it is important to first review how words such as 'chance' and 'random' are used in evolutionary biology, and then to see how often the uses of such words in biology are frequently different from the ways in which the words are understood more mathematically.

The neo-Darwinian evolutionary synthesis has two main phases: first the generation of genetic variation, second natural selection. Once the various meanings of 'chance' and 'randomness' have been discussed, we will then see how their meanings relate to these two main phases. I have drawn heavily from my book Is There Purpose in Biology? (Alexander 2017) in what follows, and that publication may be consulted by those who would like a more extensive discussion.

\section{What do we mean by 'chance' and 'random'?}

\subsection{The meanings of 'chance'}

The word 'chance' in English has many different meanings. Consider for example, the following sentences, with the meaning of 'chance' in each case in brackets after the sentence: "Is there any chance you can come for dinner tomorrow?" (enquiring about someone's availability); “There is a chance that it might rain this afternoon and interrupt the match" (a possible event that depends on chaos theory); "I met Susan down at the shops today by chance” (an unexpected encounter); “I'm buying a ticket today for the National Lottery even though I know my chances of winning anything are really low" (statistically improbable); "My chances of getting top marks in my examinations are really low” (I haven’t worked hard enough in my final year at university). 
Broadly speaking we can say that there are three main meanings of 'chance' relevant to our present topic, all being related to the question of uncertainty. The first is sometimes called epistemological chance because it refers to all those events that are perfectly law-like in how they happen, but about which we have insufficient knowledge of their antecedents to make predictions. For example, coin-tossing is used as a fair and reasonable way to decide who will start off a football match or from which end. If we had the right machines, cameras etc in place, it would be possible, in principle, for a clever observer to predict whether the coin would fall as a heads or a tails. In fact a group of mathematicians and others, mainly from Stanford University, have done just that ${ }^{1}$. They built a machine which did the coin-flipping for them, using a camera that can take up to 1400 frames per second and, with some fine adjustments, found that if the coin was flipped heads up at the start, then it would land heads up 100\% of the time. Clearly such a system would be of little use to football referees as fairness would be impossible. More encouraging was their estimate that in a normal human flip of the coin, the chances of the coin landing heads up if it was flipped heads up was 0.51 (for why this might be, refer to their rather technical paper). In other words, we might naturally assume that if we keep tossing a coin many hundreds of times and recording the results, eventually the heads:tails ratio should be $1: 1$, but other biased physical factors might be at play. For all practical purposes, however, a very small bias will not matter for a given match. Such is not the case for who wins the National Lottery. There we need many machine-generated randomly bouncing balls in order to generate the winning numbers and to be quite certain that there is no bias.

The point in all this, of course, is that if we want to be quite fair in delegating a decision to a process that has human consequences, then we are best served by building a machine to do the job. But the process used to generate the chance result is entirely orderly, reflecting the known laws of physics. If we knew all the antecedents involved, an incredibly complex amount of complex information that we will never know, then it would be

http://statweb.stanford.edu/ susan/papers/headswithJ.pdf. Accessed September 17th, 2020.

ScientiaetFides $8(2) / 2020$ 
possible, in principle, to predict the outcome. It is the fact of not knowing all this information that makes the chance process useful for us (in many circumstances).

Darwin's use of the word 'chance' in his Origin of Species was explicitly epistemological in places. As already quoted, Darwin saw that his use of the word 'chance' was "a wholly incorrect expression, but it serves to acknowledge plainly our ignorance of the cause of each particular variation" - so clearly referring to 'epistemological chance'.

The second main type of chance we can call ontological chance because there are no antecedents that could possibly be known that could enable a prediction, even in principle. So in this case it is not a question of lack of knowledge - there is no knowledge that could be known. This is sometimes called 'pure chance' because there is nothing that we can know which has predictive value. If I claimed that "It was pure chance that I met Susan down at the shops", I might be well understood in colloquial speech, but formally I would be wrong because there certainly were antecedents that could be cited to explain our unexpected meeting: for example, Susan always goes to the shops on a Saturday, like me; Susan always browses in a book-shop on Saturdays like me, and so forth. Our meeting was therefore a chance event epistemologically but not ontologically.

A classic example of ontological chance appears to be radioactive decay. We need to use the word 'appears' because we can never be $100 \%$ sure that there is not some hidden reason why a particular radioisotope (radioactive chemical) emits a particle of radiation energy at one moment rather than another. But to the best of our current knowledge there are no such hidden reasons. In practice this makes no difference in our use of radioisotopes for all kinds of purposes, not least in medical research. For example, I have spent much of my working life using the radioisotope phosphorus-32 in my experiments. The non-radioactive form of phosphorus found most commonly in our bodies is phosphorus-31 - it has just one less neutron than its radioactive counterpart. Phosphorus-32 is made in nuclear reactors and then decays by a half every 14.3 days. Even though the timing of each emission of each radioactive particle of energy is unknown, averaging out 
trillions of these events very readily generates the precise value of 14.3 days for the half-life. The same point holds for all the other many radioisotopes that are known, ranging from a half-life of fractions of a second all the way to examples like potassium- 40 which has a half-life of more than one billion years.

Ontological chance stems from quantum mechanics ${ }^{2}$. Perhaps the most famous experiment describing the quantum properties of electrons or photons of light is known as the 'two-slit experiment' (Henson 2016). We arrange a wall or other barrier with two slits in it. We bombard the wall with electrons or with photons (of light). Either the electron or the photon will go through one slit or the other in a way that is impossible to predict. Furthermore, the "particle-waves", to use the language of Richard Feynman, can go through both slits simultaneously without splitting into two separate particles. The two-slit experiment is unpredictable in principle and not just in practice - an ontologically chance event in most people's understanding of the phenomenon. Is the ontological chance of quantum mechanics at all relevant to the mechanisms of evolutionary biology? Only indirectly, without playing any kind of central role.

The reason is that in the vast majority of biological processes (including, to the best of our current knowledge, the brain), specific single events at the quantum level make no difference. This is because the processes involve the interactions of molecules, each one of which has properties that represent the 'average' of trillions of quantum events. One single quantum event makes no difference to the organism. But in photosynthesis, the process whereby the sun's energy is converted into chemical energy in plants and some bacteria, that is not the case. One single and particular quantum event in photosynthesis involves capturing the energy of a single

2 There remains much discussion in the physics literature as to whether our observations of chance quantum phenomena reflect the intrinsic behavior of basic particles - in other words whether 'chance' at this level is an objective reality, the so-called Copenhagen interpretation maintained by Walter Heisenberg - or whether there are 'hidden variables' that determine the behavior of the particles, a minority view supported by physicists such as David Bohm. The Copenhagen interpretation is the one assumed here. If the 'hidden variables' view were correct, then quantum mechanics would be a version of epistemological chance. 
photon of light from the sun and is really important. Of course when this event occurs many times, cumulatively this results in plant growth, but the process depends on such individual quantum events. Other quantum events are also involved in vision, in the actions of various enzymes, and in the mechanisms whereby animals navigate using the earth's magnetic field. But in all cases the quantum events are playing roles in overall systems which are highly organized and orderly with consistent functions and outputs (such as photosynthesis) - they are not some hidden source of 'pure chance' coming into biological processes viewed at a functional level.

But could one invoke ionising radiation as a source of 'pure chance' within the evolutionary process? For example, an ionizing radiation particle might cause the death of Lion A from cancer at one moment when that would not have happened had the particle been emitted at another moment (the lion had just entered a cave so was protected from radiation). Because of that event, Lion A was no longer alive to eat Antelope B which went on to have a large and successful family of baby antelopes. The precise trajectory of future evolution might be affected once this particular mutation had occurred. But note the proviso 'precise trajectory'. As discussed below, for natural selection to occur, the source of genetic variation is irrelevant, be it by radiation, chemical mutagens or replication errors. Natural selection ensures that the overall process is one of epistemological rather than ontological chance.

The third type of chance we might call metaphysical chance, chance that goes well beyond science. We might even call it metaphysical Chance where Chance is given a big 'C'. In 1970 the French molecular biologist Jacque Monod published Chance and Necessity (Monod 1997) in which he argued that since evolution was based on chance, so the universe was one in which Chance ruled. Monod concludes: "Man knows now that he is like a gypsy camping on the edge of the universe where he must live. The universe is deaf to his music, indifferent to his hopes, as to his suffering or his crimes". This is the idea that Chance somehow rules over everything, almost as if it were an agency or a metaphysical principle. With respect to genetic mutations Monod wrote: 
We say that these events are accidental, due to chance. And since they constitute the only possible source of modifications in the genetic text, itself the sole repository of the organism's hereditary structures, it necessarily follows that chance alone is at the source of every innovation, of all creation in the biosphere. Pure chance, absolutely free but blind, at the very root of the stupendous edifice of evolution: this central concept of modern biology is no longer one among other possible or even conceivable hypotheses. It is today the sole conceivable hypothesis, the only one compatible with observed and tested fact. And nothing warrants the supposition (or the hope) that conceptions about this should, or ever could, be revised. [Author's italics] (Monod 1997).

The scientific conclusions on the role of chance have in fact been massively revised by more recent scientific advances as will our comments below make clear. But the interesting point here is how, based on the known science of his time [1970], Monod then goes on to make metaphysical inferences, as already noted. Monod was not the first scientist to extrapolate wildly from the currently understood properties of the world to conclusions that lie well beyond science. Here we have what sounds like Tyche, the Greek goddess of chance, together with Fortuna her Roman counterpart. Chance has become an agency, the 'Lady Luck' so beloved by National Lottery winners.

Suffice it to say that Chance is not an agency and does not 'do' anything. Chance is simply our way of describing our own position as observers in relation to various properties of matter, no more and no less. Despite this obvious fact, it is remarkable how often the language of 'Chance as agent' creeps into otherwise sober scientific and philosophical texts.

\subsection{The meanings of 'random' in mathematics and in evolutionary biology}

When biologists speak of 'random' mutations in evolution, they are referring to the fact that genetic variation occurs in an organism without the well-being or otherwise of the organism in view. Their occurrence is not influenced in any way by the needs of the individual organism in which they occur. 
By contrast, in mathematics randomness has a fairly clear meaning, although with some nuances and conditions. "Mathematicians typically use the word 'random' to describe processes in which multiple outcomes can occur and each is associated with a probability that gives the likelihood of that outcome" (Giberson 2016, p. 66). This entails, for example, that if you take a string of numbers, let us say 1-100, if the numbers are randomly selected, then any single number in this series will have an equal probability of being selected. Such a series can be generated by random number generators of the kind that can be found on many computers. A traditional statistical approach then examines such a series of numbers to see whether they display the property of randomness (Bartholomew 2008, p. 62). No single number can be "random", it is rather the process whereby the numbers have been generated that can be assessed as being random, and that process can only be assessed with a long list of numbers. For example, the number in a series should not depend on a number that has just gone before. If every time that we found a 57 it was preceded by a 23 in the series, we might worry that the series was not truly random, and indeed the series might then in part become predictable. If it were genuinely random, it could not be predictable. So no part of the series should provide any information about the properties of any other part of the series. However, we need to be careful at this point, because in a series of ten randomized numbers picked from 1-100 it is entirely feasible, if we continue to use our random number generator long enough, that we will come up with 23-23-23-23-23-23-23-23-23-23. This does not look random, but every number in the series $1-100$ has an equal chance (1 in 100) of being chosen, so the series of $23 \mathrm{~s}$ just shown is no more or less likely than any other series of ten numbers from 1-100. Furthermore, if we randomized that series to 11 numbers, then the eleventh number could be 72 - in other words, a random series of ten 23 s provides no expectation that the eleventh number is going to be a 23: the series is non-predictive.

Now if we apply the mathematical meaning of 'random' to the mutations that lead to the genetic variation necessary for natural selection to occur, we find that they are non-random. If mutations in the 3.2 billion nucleotides that make up our own human DNA were truly random, then they would be 
equally likely to occur at any position, but this is not the case. For example, in a recent Dutch study 250 family trios (father, mother, offspring) had their genomes completely sequenced (Francioli et al. 2015). Given that an average 38 new mutations appeared in the newborn that were not there in the parents, if they were randomly distributed throughout the genome, then on average there should be some sizable gaps between them. In fact some simple maths (divide 38 into 3.2 billion) suggests that they should be separated by a median of around 84 million nucleotides. But they are not. For example, the researchers found that there were 78 instances in which there were clusters of 2-3 mutations found within 20,000 nucleotides of each other, which is a very much smaller number than 84 million. Several factors are likely to cause this clustering, although the phenomenon is not yet fully understood.

For example, it has long been known that mutations are more likely to occur where the sequence $\mathrm{CpG}$ is found in the DNA sequence. This means that the base cytosine has a guanine next to it, and the "p" refers to a phosphate group that links the two together in the long chain of nucleotides making up the DNA. Cytosines are more likely to be methylated where this sequence is found. This involves the transfer of a 'methyl' chemical group on to the cytosine which is really important because if that region of the DNA encodes a gene, this has the effect of 'silencing' the gene, which means inhibiting or even entirely switching off its expression. This is one of the key mechanisms involved in epigenetics. Epigenetics denotes all the various ways in which the DNA itself, or its surrounding proteins, are chemically modified in order to switch genes on or off. In mammals 70-80 percent of CpG sequence units are methylated at any one time, whereas only 2 to 5 percent of all cytosines are methylated (remember that most cytosines do not have an adjacent $\mathrm{G}$ - they need an adjacent $\mathrm{G}$ to get methylated).

Methylcytosines are particularly prone to be mutated for chemical reasons that need not detain us here. Despite the fact that in human DNA only a few percent of the nucleotides are methylcytosine, about 30 percent of all point mutations are found at these sites. So the epigenetic modifications that increase cytosine methylation also increase the chance of permanent 
DNA mutations occurring at those particular positions in the DNA sequence. Epigenetic modifications can "channel" mutations so that they are more likely to occur in one place than another. This explains the fascinating fact that we can cause the probability of more mutations appearing in our own cells by the choices we make, choices which in turn impact on the methylation of our genome. For example, smoking changes the methylation status of the DNA in cells in the lungs which may contribute to the many mutations in lung cells caused by this toxic habit, eventually leading to cancer in many cases.

Coming back to the Dutch study, here paternal age is clearly a critical factor in the number of mutations appearing in the newborn. The methylation status of the genome of germ-line cells changes with the number of replication cycles that they have undergone during their generation (more in older men), and the CpG units that are methylated, and so more likely to mutate, are not evenly distributed throughout the genome. This could certainly be one reason for the non-random distribution of mutations in the newborn, but other factors are clearly at play as well.

Investigating the clustering of mutations in our own human offspring is clearly of great personal interest, but humans are not the easiest species in which to look at detailed mechanisms. It is much simpler to investigate the same question in rapidly dividing cells in the laboratory, such as yeast cells. In one study yeast cells were exposed to a mutagen and then had their genomes sequenced soon after to see where the mutations were found (Chan and Gordenin 2015). The striking finding was that out of an average 45 new mutations, there was a cluster of 26 mutations in one particular region of chromosome 2, whereas only 19 mutations were found in the whole of the rest of the genome. Therefore once again genetic mutations are very far from being random in a mathematical sense.

The unequal distribution of mutations in the genome has been demonstrated in numerous studies (Rogozin and Pavlov 2003) and a recent review listed around eight different ways in which the molecular machinery involved in DNA replication can lead to a greater probability that mutation clusters occur rather than mutations being randomly distributed (Chan and Gordenin 
2015). The biochemistry of such analyses can be quite complex and will not be discussed here, but in each case it's worth noting that mutations are caused by molecular mechanisms that in many cases are now largely understood and where predictability based on the knowledge of antecedents could be possible in principle, albeit not in practice. One major source of mutations is the inability of DNA repair enzymes to be $100 \%$ efficient in repairing the DNA replication errors that frequently occur.

The generation of genomic 'mutational hot-spots' is thought to have been critical in our own human evolution. This became apparent by a detailed comparison of the human and chimpanzee genome sequences. Based on the 'genetic mutation clock', our last common ancestor with the chimp is estimated at around 5-6 million years ago. Not surprisingly there has been a lot of interest in the genetic factors that contribute to us being so different from our chimp cousins, not least in the fact that we have brains that are more than three times larger. Several so-called 'Human Accelerated Regions' have been found in the human genome that are quite different from the chimp genome (Burbano et al. 2014). These are regions of rapid mutation in which more mutations have accumulated during ten million years of primate evolution than in all the previous one hundred million years of mammalian evolution. Other studies have identified an enzyme, originally involved in providing protection against viral attack, now involved in introducing mutational clusters into hominid genome sequences (Pinto et al. 2016). The enzyme can even cause a 'shower' of new mutations clustered together in one region of the genome in a single generation. As this enzyme became more 'switched on' during the course of evolution so, it is thought, did hominin evolution speed up as new genetic information came into the genome.

\subsection{What types of chance are involved in generating genetic variation?}

We have so far focused on mutations as a source of the genetic variation which provides the 'raw material' for natural selection. In practice the sources of genetic variation are far broader than specific mutations, and include sexual 
reproduction, gene flow, retroviral insertions, chromosomal rearrangements, as well as other mechanisms. But from the perspective of natural selection, it is of no consequence how the variation arises. Providing the variation makes some difference to the progeny, then natural selection is in operation.

With this information as background, we can now assess the processes involved in generating genetic variation according to the three different understandings of 'chance' out-lined above. Clearly there is plenty of epistemological chance involved in the mechanisms of mutation. The mechanisms are generally far too complex to make any specific predictions as far as individual mutations are concerned. However, once we start averaging large numbers, then well-justified generalisations can be made about such items as mutation rates, where mutations are more likely to occur in the genome, which chromosomes are more likely to undergo structural changes, and so on. Furthermore, in many cases we are improving our understanding of the molecular mechanisms underlying mutational changes and these mechanisms follow the normal rules of physics and chemistry. In some cases we are able to link susceptibility of particular regions of the genome to mutational change with the evolution of the organisms involved. The 'Human Accelerated Regions' could be an example of this. Mutation rates have to be 'set' just right in different parts of the genome to facilitate evolvability. If there were no mutations at all, then life would be completely static and there would be no evolution, so no carbon-based life on earth beyond, perhaps, some very early replicating life-forms. But if mutations were completely unrestrained then nothing would be alive because all the information in the genome would end up as gibberish. In fact it has been estimated that at least 10,000 DNA damage events occur every day in every cell of the human body (remembering that our bodies contain around $10^{13}$ cells) $)^{3}$. So there has to be a 'mutation thermostat' that controls the mutation rate. A key buffer that corresponds to the lowering of the thermostat is provided by the repair enzymes that recognize errors in the DNA sequence in its newly replicated strands and ensure that they are repaired back to the

3 https://news.vanderbilt.edu/2015/10/29/new-class-of-dna-repair-enzyme-discovered/. Accessed $19^{\text {th }}$ September, 2020. 
proper sequence. There are many different repair systems and they ensure the remarkable fidelity of replication of DNA. Without them we would all be dead from cancer rather quickly.

What about ontological chance? The emission of radioactive particles, as noted, displays quantum uncertainty, so represents 'pure chance', not something that could be predicted even in principle, at least not in its precise timing. Ionising radiation causes mutations in DNA by directly breaking the chemical bonds that hold the nucleotides together. As discussed already, the radioactive properties of each radioisotope are known with some precision and their average outputs and consequent average effects on DNA can likewise be predicted. But it is impossible, even in principle, to predict the timing of individual mutational events. Could this then contribute to the idea that evolution is a theory of chance? Not really, because the natural selection considered in the next section acts as the stringent sieve that selects which mutations will be maintained in a population and which will be discarded. The sieve potentially operates on any kind of genetic variation, irrespective of how it was produced.

For the sake of completeness, we should also ask the question as to whether metaphysical chance could in some way be derived from the various ways in which genetic variation occurs in the genome. Jacques Monod thought the answer was "yes". But even based on the limited knowledge of molecular biology known at that time, it is hard to see how or why one might wish to extrapolate from the properties of cells to ultimate questions about the universe and its meaning. Furthermore, even if one thought that was possible and logical, half a century later the molecular biology looks very different. We now know that many types of mutation are not really random anyway in the mathematical sense in terms of their clustered distribution through the genome, as we have just been discussing (although systematic studies of the type described have not yet been carried out on every type of mutation). The lack of randomness in the origins of genetic variation highlights the risk of linking one's philosophy to scientific theories or understandings. Science moves on very fast and so the philosophy in question can be very quickly widowed. 


\subsection{Natural Selection}

We now come to the second main phase of the evolutionary process. Darwin used the phrase 'natural selection' in order to distinguish the process from the human selection involved in domestic breeding of animals such as pigeons (Darwin spent a lot of time investigating pigeon-breeding).

In contemporary evolutionary theory, 'Natural selection is the differential reproduction of alternative genetic variations, determined by the fact that some variations are beneficial because they increase the probability that the organisms having them will live longer or be more fertile than organisms having alternative variations. Over the generations beneficial variations will be preserved and multiplied; injurious or less beneficial variations will be eliminated' (Ayala 2007).

In practice much variation in genomes is selectively neutral. In other words, this is the kind of variation that really makes no difference to the organism in question. If we have one amino acid rather than another at the 816th position in the string of amino acids that make up a particular protein, it really makes no difference either way. So the variant amino acids at that particular position will drift around in a population (through breeding) without any effects, beneficial or otherwise, on the carrier. But as neutral mutations accumulate in the genome of an individual, there may come a day when a new functionality comes into being as these genes interact in some way, either via their protein products and/or as a consequence of regulatory sequences, and in that case natural selection may begin to operate.

When genetic variation does make a difference to the organism, for good or for ill, the organism will tend to leave, over many generations, greater or fewer numbers of offspring - 'reproductive success'. The term 'survival of the fittest'4 has sometimes been used to describe natural selection, but is not very accurate because survival is not really the main point in this process. Of course if an animal does not survive then it will not reproduce,

4 'Fittest' in evolutionary biology has a technical meaning which refers not to the strength or agility of a particular organism, but rather to its ability to generate most progeny for the next generation in comparison with other individuals within an inter-breeding population. 
but the key point about natural selection is the successful reproduction that ensures that an individual's genes are passed on to the next generation.

Natural selection therefore acts as a rigorous filter to reduce the amount of genetic variation in a population. It is a very conservative mechanism. The reason for this is that the great majority of genetic changes, if not neutral, are likely to be deleterious for the organism, and it is these that will be removed from the population after some generations - or even immediately if lethal - since they lower reproductive success. On the other hand, the few beneficial changes that will readily pass through the filter of natural selection will quickly spread throughout an interbreeding population as they bestow reproductive benefits on their recipients. The term 'selective sweep' is used to describe the rapid spread of a beneficial genetic variant through such a population.

Just how conservative natural selection is in its operation may be illustrated by the conservation of the amino acid sequence of many proteins that are essential to biological life as we know it. For example, cytochrome c plays a crucial role in the energy production of cells required to keep them alive in the presence of oxygen and is found in virtually all animals and plants. It is a small protein, generally around 105 amino acids in length. Change of a single amino acid at certain critical positions in the protein leads to loss of function and the death of the organism. This explains why the amino acid sequence of this protein is conserved across species. For example, humans share $97 \%$ sequence identity of cytochrome c with the rhesus monkey, $87 \%$ with the dog, $82 \%$ with the bat, $67 \%$ with the fruit-fly, $64 \%$ with the moth and $44 \%$ with yeast with which we last shared a common ancestor about a billion years ago (Keya and Priya 2016). Natural selection is a really conservative process.

As already mentioned, not all genetic variation will be 'seen' by natural selection because it makes no difference to the fitness of the organism. 'Genetic drift' is also relevant to this point. This refers to the variation in the relative frequency of different genotypes in a small population, owing to the chance disappearance of particular genes as individuals die or do not reproduce. 'Chance' here is epistemological chance: there are very 
good reasons why an animal might die young before getting the chance to reproduce. For example, it might be eaten by a lion. So 'genetic drift' can involve useful genes that natural selection would operate on had it been given the opportunity, but the opportunity never came. Genetic drift, like natural selection, is therefore a mechanism for reducing the amount of genetic variation in a population.

As already highlighted, it should by now be clear why it does not really matter whether variation comes into the genome via the pathway of epistemological chance (most of it) or ontological chance (as in radiation effects), as in both cases the winnowing effects of natural selection are most influential in bringing about certain constrained outcomes. Natural selection is like the potter moulding the clay - over a long period of time the consequences of genetic variation are moulded by the potter of natural selection to shape an inter-breeding population into a slightly different collection of phenotypes.

Genetic variation plus natural selection are the central mechanisms in Darwinian evolution. But clearly there are many other events that impinge on the process. Around 65 million years ago a huge asteroid struck the earth, estimated to be up to nine miles in diameter, which left a massive crater (called the Chicxulub crater) about 112 miles in diameter and 30 miles deep buried beneath the sediments off the Yucatan coast in the Gulf of Mexico. It was this catastrophe that probably contributed to the demise of the dinosaurs, along with increased volcanic activity around this time. But as the earth recovered from the shock and climates were restored, so new opportunities were created for adaptive radiation, the process whereby rapid diversification of species occurs in order to fill up a collection of empty ecological niches. This is how primates began to get a real foot-hold on the planet, becoming more common about 50 million years ago. The 200 primate species alive today, including us, represent the remains of an adaptive radiation that probably gave rise to about 6,000 species altogether.

So do such 'chance events' as the hitting of the earth by a large asteroid, so altering the history of evolution during the past 65 million years, not suggest that evolution taken as a whole is a 'chance process'? It seems not. 
Clearly there is plenty of epistemological chance here, given that there is no way that we could describe all the antecedents of these processes. However, it is worth noting that the orbits of asteroids, at least large ones, are now well known. Asteroid orbits are, in principle, as predictable as earth or sun orbits. In any event, had the asteroid not hit earth 65 million years ago, the dinosaurs would have eventually gone extinct anyway, perhaps for climatic reasons, as all species eventually do, especially species comprising large animals. Darwinian processes end up with replenishing the earth once again in the end, even though there may be some big extinctions along the way.

None of the above should be interpreted as if genetic variation plus natural selection were the only two phases of the evolutionary process. There are plenty of other candidates that play important roles also in the overall process although evolutionary biologists are somewhat divided on their relevance. But the important point here is that none of these ideas or factors introduces the idea that evolution is a chance process; instead they tend in the other direction, highlighting constraint and convergence.

So is evolution a chance process taken overall? Dawkins is right, it does not look like it. Mutations are indeed random in the trivial sense that they happen without the organism in mind, but this is hardly relevant to the main question. More significant is the fact that the generation of genetic diversity is not random in the mathematical sense, because mutations are not evenly distributed across the genome. In any event the winnowing necessity of natural selection generally plays the most important role in the end. Certainly there are plenty of chance events involved of the epistemological variety (asteroids hitting the earth, and so forth). But the system as a whole is incredibly fine-tuned to bring about a carefully orchestrated balance between stasis and change. We are the fortunate beneficiaries of this history of fine-tuning.

\section{Constraint during biological evolution}

So far our discussion of chance in evolution has been mainly focused at the genetic level. In practice most biologists studying evolution are investigating 
animals and plants at the population level. At this level also many striking observations illustrate the point that evolution is very far from being a chance or random process.

The best known example of this point is that of 'convergence' which has been thoroughly discussed in several books (Conway Morris 2003, Conway Morris 2015, Dawkins 2016). Evolutionary convergence refers to the repeated but independent development of the same biochemical pathway, or organ or structure in different biological lineages. In other words, as animals or plants face the challenges of adapting to particular environments, so at independent times and in independent circumstances the evolutionary process has converged on the same adaptive solution, in hundreds of cases generating very similar ways of meeting the challenge. Some of these adaptations are so remarkably similar that it is difficult to believe that a particular species with the adaptive structure did not evolve from the other, but such is not the case. A single example of convergence will be provided here to illustrate this point, although many hundreds of examples could be cited.

\subsection{Evolution of the Eye}

One of the most famous examples of convergence is the evolution of the eye, Darwin's “organ of extreme perfection” (Darwin 1859). 96\% of all animal species contain a complex optical system (Land and Fernald 1992). There are ten main types of eye, but most fall into two categories, camera eyes or compound eyes. Despite their complexity, both types have evolved independently multiple times in quite different evolutionary lineages, perhaps more than 40 times (Salvini-Plawen and Mayr 1977). Compound eyes, typical of arthropods like crabs and of insects like bees, generally consist of thousands of individual photoreceptor units arranged on a convex surface pointing outwards, and the image perceived is a composite of all the signals received from each separate unit. The net result is a pattern of light and dark, a bit like the halftone illustrations in a newspaper or magazine. Compound eyes are good at detecting movement, but overall camera eyes 
are much more efficient. For example, if we humans had compound eyes instead of the camera eyes we in fact have, then our eyes would each need a radius of around 30 feet to obtain the same visual acuity, which would be inconvenient to say the least. It was the Lutheran astronomer Johannes Kepler back in the early $17^{\text {th }}$ century who first understood how the human eye works, described in a publication generally considered to be the foundation of modern optics (Kepler 1604). As the name suggests, camera eyes work on the same principle as a pin-hole camera, with light entering the eye via the pupil and passing through the gel inside to focus on the retina, a network of light-sensitive photoreceptor cells that then send the messages to the brain where they are integrated to construct a composite image. Animals that have camera eyes, such as squid, jellyfish, spiders, and vertebrates like us, are typically predatory and very active, requiring good visual acuity to catch their prey.

An example of convergence that has been recognized now for more than a century is that between the camera eyes of cephalopods like squid and octopus and the eyes of vertebrates. The similarities are striking, with some interesting differences also. In our eyes we have a 'blind spot' due to the exit of the nerves from the retinal photoreceptors in a bundle in the middle of the retina so that light cannot be detected in that particular area. The camera eyes of the squid and octopus are better arranged in this respect in that the nerves leave the retina from the back-side before being gathered into a bundle so there is no 'blind-spot'. In practice our brains fill in the missing information, so it does not make much difference either way. In the present context the important point to note is that the evolution of cephalopod and vertebrate camera eyes has occurred in evolutionary lineages separated by millions of years of evolutionary time (Fernald 2006).

The evolution of compound eyes well illustrate evolutionary convergence. The annelids are a very large phylum containing around 17,000 different living species, including the well-known earthworm, as well as leeches. Compound eyes are frequently found amongst this great collection of species and in a group called the sabellids this type of eye has evolved independently several times; likewise in the bivalve molluscs, of which 
there are around 9,200 living species, including the well-known oysters that some enjoy for dinner (Conway Morris 2003). Not all arthropods contain compound eyes, but many do, and there is good evidence that they have reappeared more than once in separate lineages (Oakley 2003). It should be noted in such examples that convergence does not imply that eyes arose de novo each time, but rather that the genetic resources, or at least some of the resources, were available when the selection pressure was once more 'on' to generate this particularly useful adaptation. For example, compound eyes are often found in arthropods deep down in the ocean where they are useful for collecting very small amounts of light.

Many useful accounts of convergence in eye evolution are available ${ }^{5}$. The important conclusion is that if you live on a planet of light and darkness then you are very likely to get eyes at some stage of evolution. As Dawkins comments: "It seems that life, at least as we know it on this planet, is almost indecently eager to evolve eyes" (Dawkins 2016). The adaptive advantages are huge and obvious. This even led Dawkins to suggest that evolution is 'progressive', a notion that Darwin himself found problematic, Dawkins writes: "the cumulative build-up of complex adaptations like eyes, strongly suggests a version of progress - especially when coupled in imagination with some of the wonderful products of convergent evolution” (Dawkins 2016).

\section{Chance, Evolution and Theology}

The concern that in some way 'chance' is incompatible with order and therefore with God's action or will, has deep philosophical roots. Aristotelian science was influential well into the seventeenth century. In Aristotle, the physis of nature refers to the intrinsic properties of things which rarely

\footnotetext{
More extensive accounts describing the convergence of eye evolution can be found in Dawkins, Richard. 1996. Climbing Mount Improbable, London: Viking; Conway Morris, S. 2003. Life's Solution: Inevitable Humans in a Lonely Universe, Cambridge: Cambridge University Press; Dawkins, Richard. 2016. The Ancestor's Tale: A Pilgrimage to the Dawn of Life 2nd Edn, London: Weidenfeld \& Nicolson; Conway Morris, S. 2015. The Runes of Evolution: How the Universe Became Self-Aware, West Conshohocken, PA: Templeton Press.
} 
change; this is contrasted with 'chance' or 'the accidental' (Aristotle 1984) which thereby become a challenge to the possibility of scientific explanations. But Aristotelian science was in turn challenged by the early Jewish and Christian natural philosophers for whom 'natural' meant 'created by God'. The fact that the universe could be described by universal mathematical laws depended not upon the inherent virtues or powers of natural objects which direct them towards particular ends, but upon God who is the cause of all things. The laws of motion, says Descartes, 'follow manifestly from the mere fact that God is immutable and that, acting always in the same way, he always produces the same effect' (Descartes 1985) ${ }^{7}$.

Biblical texts provide clear examples of the ways in which God is seen as acting providentially through what we might now wish to call epistemological chance events. When the prophet Micaiah predicted that King Ahab would be killed in battle at Ramoth Gilead (1 Kings 22:15-28), this indeed came to pass, but it happened by someone who 'drew his bow at random and hit the king of Israel between the sections of his armour' (I Kings 22:34, my italics). As Proverbs 16:33 so vividly puts the point: 'The lot is cast into the lap, but its every decision is from the Lord'. The Bible sees God's works occurring equally in all the various manifestations of his activity, whether in the more 'law-like' workings of the natural world (Psalm 33:6-11), in chance events (Proverbs 16:33), or in his control of the weather (Psalm 148:8), which today we describe using chaos theory. There is never a hint in the Bible that certain types of event in the natural world are any more or any less the activity of God than other events. It is therefore no surprise to find the disciples casting lots in Acts [1:26] as a way of appointing someone to apostolic ministry in order to replace Judas. However, after the giving of the Holy Spirit at Pentecost, the early church then subsequently depended upon the advice of their leaders and the guidance of the Spirit in their decision-making, as in Acts 15.

Taking evolutionary history as a whole, it is difficult to know why this should be seen as in any way incompatible with belief in a creator

Aristotle. Physics 197a31-35, 196b, 15-16.

7 Descartes. (1985, I, 90-1, 93-6; cf. 240-9). 
God whose providential intentions and purposes are being worked out through the whole process. As Dawkins points out, simply from a biological perspective it is hard not to see the evolutionary process as progressive. Sean Carroll, a well-known evolutionary biologist from the University of Wisconson-Madison, remarks in a review in Nature: 'Life's contingent history could be viewed as an argument against any direction or pattern in the course of evolution or the shape of life. But it is obvious that larger and more complex life forms have evolved from simple unicellular ancestors and that various innovations were necessary for the evolution of new means of living' (Carroll 2001). Carroll chooses his words carefully, but if pressed every biologist has to admit that multicellular organisms are more complex than bacteria, that mammals are in some sense more advanced than yeast, and that the human brain has more capacities than that of a shrew. So it is perverse to deny some form of directionality to the arrow of biological time.

One useful way to envisage history as viewed through the lens of evolution is to imagine the whole 4.6 billion year history of the earth as being crammed into a single day. Simple forms of life would already be appearing by 2.40 a.m. with single-celled organisms (prokaryotes) flourishing by around 5.20 a.m. The great oceans of the world start to change colour as cyanobacteria (blue-green algae) spread across the planet. At the same time the genetic code becomes established that will dominate the generation of biological diversity for the remainder of the day. After this early-morning start, there would then be quite a long wait until single-celled organisms containing nuclei (eukaryotes) become visible around lunch-time. A further seven hours pass before multicellular organisms start appearing in the sea by 8.15 in the evening. About half-an-hour later the planet changes colour as cyanobacteria and green algae invade the land. The Cambrian explosion starts at 9.10 p.m. and in an amazing three minutes an immense diversity of phyla appear, each with a distinctive body-plan, with many of the anatomical features introduced continuing in many of the phyla right up to midnight. Twenty minutes later plants start appearing on land for the first time, followed very soon afterwards by the earliest land animals. At 10.11 reptiles 
start roaming the land, followed half an hour later by the mass extinctions which mark the end of the Palaeozoic period. By 10.50 p.m. the earliest mammals and dinosaurs are appearing and by 11.15 the sky begins to fill with birds. Just two minutes before midnight hominids start to appear and a mere three seconds before midnight anatomically modern humans make their entry onto the scene, the whole of recorded human history until now being compressed into less than one fifth of the second before midnight, the mere blink of a human eyelid. Theists will see the providential activity of God throughout this great 'drama of life'.

A strong belief in the providence of God perhaps helps to explain why Darwin's new theory was accepted most readily by those in the reformed Christian tradition following the publication of The Origin of Species in 1859 , although clearly there were many in other theological traditions who did likewise. It is just that the acceptance is sufficiently striking to draw the attention of historians who have written on the early reception of Darwin's theory, such as James Moore (Moore 1981) and David Livingstone (Livingstone 1987). For example, the theologian and geologist George Wright (1838-1921), whose books on glacial geology were for years the standard texts on the subject, was not only a vigorous proponent of Darwinism, but held, as Moore points out, 'that Darwin's work actually allies itself with the Reformed faith in discouraging romantic, sentimental, and optimistic interpretations of nature' (Moore 1981). Wright even wrote 'that Darwinism has not improperly been styled 'the Calvinistic interpretation of nature'.

James Dana, professor of natural history at Yale, and editor of The American Journal of Science, was another American geologist of orthodox Christian conviction who accepted Darwinian evolution after some initial doubts, initiating an influential series of lectures on evolution at Yale in 1883. Dana's concluding remarks of his opening lecture are informative, because they summarise what was clearly an influential opinion in Christian American academic circles of the late nineteenth century

1. That it is not atheism to believe in a development theory, if it be admitted at the same time that Nature exists by the will and continued act of God. 
2. That we cannot tell when we have ascertained the last limit of discovery with regard to secondary causes.

3. That God is ever near us, ever working in and through Nature... (Moore 1981).

Just as scientists and theologians embraced Darwin's theory in the late $19^{\text {th }}$ century, some after initial hesitations, so there seems little reason why this should not be the case today. Certainly there seems to be no reason to be theologically suspicious of the theory because it is a 'theory of chance'. As we have noted here, such is not the case, and we should be thankful to God that he has brought about our own existence by such a creative process.

\section{References}

Alexander, Denis R. 2017. Is There Purpose in Biology? Oxford: Monarch.

Aristotle 1984. The Complete Works of Aristotle, Revised Oxford Translation, edited by Jonathan Barnes. Princeton: Bollingen.

Ayala, Francisco Jose. 2007. Darwin's Gift to Science and Religion. Washington, D.C.: Joseph Henry Press.

Burbano, Hernan A., Richard E. Green, , Tomislav Maricic, et al. 2014. "Analysis of Human Accelerated DNA Regions Using Archaic Hominin Genomes.” PLoS One 7: e32877.

Carroll, Sean B. 2001. "Chance and Necessity: The Evolution of Morphological Complexity and Diversity.” Nature 409: 1102-9.

Chan, Kin, \& Dmitry A. Gordenin. 2015. "Clusters of Multiple Mutations: Incidence and Molecular Mechanisms.” Annu Rev Genet 49: 243-67.

Conway Morris, Simon. 2003. Life's Solution: Inevitable Humans in a Lonely Universe. Cambridge: Cambridge University Press.

Conway Morris, Simon. 2015. The Runes of Evolution: How the Universe Became SelfAware. West Conshohocken, PA: Templeton Press.

Darwin, Charles. 1859. On the Origin of Species by Means of a Natural Selection, or the Preservation of Favored Races in the Struggle for Life. London: Murray.

Darwin, Charles. 1888. The Origin of Species ... Sixth Edition ... Thirty-Third Thousand. London: John Murray.

Dawkins, Richard. 1996. Climbing Mount Improbable. London: Viking.

Dawkins, Richard. 2016. The Ancestor's Tale: A Pilgrimage to the Dawn of Life 2nd Edn. London: Weidenfeld \& Nicolson. 
Descartes, René. 1985. The Philosophical Writings of Descartes, 2 Vols., Tr. John Cottinghman, Robert Stoothoff and Dugald Murdoch. Cambridge: Cambridge University Press.

Fernald, Russel D. 2006. “Casting a Genetic Light on the Evolution of Eyes.” Science 313: 1914-8.

Francioli, Laurent C., Paz P. Polak, Amnon Koren, et al. 2015. “Genome-Wide Patterns and Properties of De Novo Mutations in Humans." Nat Genet 47: 822-6.

Henson, Shaun. 2016. “Throwing Dice? Thoughts of God in a Quantum World.” In: Abraham's Dice: Chance and Providence in the Monotheistic Traditions, edited by Karl W. Giberson. New York, NY: Oxford University Press.

Kepler, Johannes. 1604. Astronomiae Pars Optica Manuscript Presented to Rudolf Ii, Holy Roman Emperor.

Keya, Kulkarni, \& Sundarrajan Priya. 2016. “A Study of Phylogenetic Relationships and Homology of Cytochrome C Using Bioinformatics.” Int. Res. J. of Science \& Engineering 4: 65-75.

Land, Michael F., \& Russell D. Fernald. 1992. “The Evolution of Eyes.” Annu Rev Neurosci 15: 1-29.

Livingstone, David N. 1987. Darwin's Forgotten Defenders: The Encounter between Evangelical Theology and Evolutionary Thought. Edinburgh: Scottish Academic Press.

Monod, Jacques. 1997. Chance and Necessity: An Essay on the Natural Philosophy of Modern Biology. London: Penguin.

Moore, James. 1981. The Post-Darwinian Controversies: A Study of the Protestant Struggle to Come to Terms with Darwin in Great Britain and America, 1870-1900. Cambridge: Cambridge University Press.

Oakley, Todd H. 2003. “On Homology of Arthropod Compound Eyes.” Integr Comp Biol 43: 522-30.

Pinto, Yishay, Orshay Gabay, Leonardo Arbiza, et al. 2016. “Clustered Mutations in Hominid Genome Evolution Are Consistent with Apobec3g Enzymatic Activity.” Genome Res 26: 579-87.

Rogozin, Igor B., \& Youri I. Pavlov. 2003. “Theoretical Analysis of Mutation Hotspots and Their DNA Sequence Context Specificity.” Mutat Res 544: 65-85.

Salvini-Plawen, Luitfried, \& Mayr, Ernst. 1977. "On the Evolution of Photoreceptors and Eyes.” Evolutionary Biology 10: 207-263. 